\title{
Individualism and attitudes towards reporting corruption: evidence from post-communist economies
}

\author{
Chiara Amini ${ }^{1}$, Elodie Douarin ${ }^{1 \star(D)}$ and Tim Hinks ${ }^{2}$ \\ ${ }^{1}$ School of Slavonic and East European Studies, University College London, London, UK and ${ }^{2}$ University of West of England, \\ Bristol, UK \\ *Corresponding author. Email: e.douarin@ucl.ac.uk
}

(Received 5 June 2020; revised 9 December 2020; accepted 9 December 2020; first published online 4 February 2021)

\begin{abstract}
Individualistic values are often presented as promoting economic development; however, their links to relevant behaviour and preferences at the micro-level remain under-explored. Here we investigate the relationship between individualistic values and personal attitudes towards reporting corruption. Unlike much of the previous research which focuses on attitudes towards corruption, we analyse the micro-level mechanisms relating to one's willingness to escape the status quo and act against corruption. We also focus on a region associated with persistently high levels of perceived corruption. Our findings indicate that individualism is associated with a greater likelihood to act against corruption. The effect estimated is small but highly significant and robust to changes in estimators and specifications. We also find evidence that institutional trust and individualism strengthen each other to generate greater willingness to report corruption.
\end{abstract}

Key words: Corruption, Individualism, Institutional trust, Anti-corruption, Culture

\section{Introduction}

While there is a strong consensus regarding the importance of institutions for economic development, there is still much to learn about the role of informal institutions, embodied in culture and human values. The importance of informal institutions is however widely recognised with North (1990) arguing that formal and informal institutions jointly regulate human behaviour, by forming sets of rules and constraints that people need to accommodate. Consistent with this definition, cultural values reflect mental schemas, acquired through socialisation, which guide behaviour, by shaping what is appropriate or not in a given social context (Hofstede et al., 2010). To the extent that these mental schema shape behaviours, they should also be important to our understanding of development.

Accordingly, a growing literature has emerged highlighting the special place of 'individualistic' values in supporting economic development and prosperity through developing efficient market institutions and good governance (Hofstede, 2001; Kyriacou, 2016; Licht et al., 2007), when compared to 'collectivist' values (e.g. Gorodnichenko and Roland, 2011, 2012). This is because individualist societies promote meritocracy and universalistic principles, rather than clientelistic networks and patronage (e.g. Tanzi, 1994, in a discussion of the feasibility of arms-length transactions, echoing 'the amoral familism' of Banfield, 1958). A long-term macro-association between individualism and economic development is thus well established. In addition to this, individualism is also about autonomy, low obedience and non-conformity (Hofstede, 2001). It can thus be associated with promoting deviation from societal norms (Triandis, 2001) or tolerating behaviours that 'are not representative of a society's

(c) Millennium Economics Ltd 2021. This is an Open Access article, distributed under the terms of the Creative Commons Attribution licence (http://creativecommons.org/licenses/by/4.0/), which permits unrestricted re-use, distribution, and reproduction in any medium, provided the original work is properly cited. 
majority' (Beugelsdijk et al., 2015: 229). A tendency which could be particularly valuable in challenging the status-quo and promoting change for the common good. Accordingly, at the individual level, individualism has been shown to be associated with greater support for individual freedom and equality (e.g. Davis and Williamson, 2019 on gender roles) and with a greater propensity to act pro-socially, especially in more collectivist settings (Andriani and Sabatini, 2015; Irwin, 2009).

With this in mind, we propose here to investigate how individualism is related to the pro-social, status-quo challenging view that corruption should be reported ${ }^{1}$. We focus on ex-communist countries only, because there, corruption rates are some of the highest in the world and have even sometimes increased in the transitional period following the collapse of communism (Havrylyshyn, 2020: 219). In addition, some have presented corruption in the region as a legacy of communism (Levin and Satarov, 2000), presenting corruption as inherited from the 'economy of favours' that developed to cope with the shortages and constraints of communism (Ledeneva, 1998).

Our findings suggest that individual-level individualism is an important factor that can explain people's likelihood to challenge corrupt practices in ex-communist countries, thus reflecting an individual demand for better institutions. This result remains after controlling for perceived institutional quality and there is some evidence that institutional trust and individualism strengthen each other to generate greater willingness to report corruption.

We contribute to a small literature trying to establish the micro-level mechanisms through which cultural values can lead to better institutional quality (e.g. Pitlik and Rode, 2017), focusing on a rarely investigated activity: the reporting of corruption. Secondly, we contribute to the understanding of the role institutional trust plays in fighting corruption. We provide evidence that institutional trust is an important driver of anti-corruption activities, even in the relatively low trust context of the communist countries we are investigating (Denisova et al., 2010), as it reinforces the positive association between individual-level individualism and a respondent's propensity to report corrupt practices.

Section 2 provides a discussion of individualism and collectivism and on the quality of institutions within a context of high levels of corruption in ex-communist countries. Section 3 explains the data and methodology used. Section 4 reports our results. Section 5 presents a heterogeneity analysis. Finally, section 6 discusses the results further and concludes.

\section{Literature review}

Recent research has shown that culture is an important determinant of economic expectations and preferences, which in turn can have a direct impact on economic outcomes (Guiso et al, 2006). Dissecting culture is a challenging task but the individualism-collectivism distinction is recognised as especially important in explaining cultural variation at the national level (Heine, 2007; Hofstede, $1991)^{2}$. Individualistic societies are characterised by the primacy of the self over society, in the sense that self-achievement and control are strongly valued (Hofstede, 1991; Schwartz, 1990). In contrast, collectivist societies weigh the action and interest of the group over the individual. In this context, maintaining the cohesion of the group is particularly important (Triandis, 2001) and behaviour is strongly guided by social norms, with a breach of these norms bringing some level of punishment.

Fukuyama (2011, 2014) and Tanzi (1994) argue that in collectivist and patrimonial societies, respectively, the public sphere is characterised by clientelistic networks that fuel corruption, whereas the public sphere in individualistic societies is based on meritocracy which results in better quality formal institutions (e.g. legal system, property rights). In line with this, Kyriacou (2016) finds evidence that individualistic societies can improve economic outcomes by causing better quality institutions

\footnotetext{
${ }^{1}$ In this paper, we consider corruption as taking place both in the private and the public spheres (see Hodgson and Jiang, 2007).

${ }^{2}$ Individualism has drawn a great deal of attention in the literature, in fact a recent survey of studies in business and psychology shows that most analyses building on Hofstede's dimensions focus on individualism-collectivism (Kirkman et al., 2006).
} 
concluding, amongst other things, that these societies should achieve lower levels of corruption as a result. Within this context, ex-communist countries are important to study since they have recently moved to a market-based system with a reduction in government size and increased surveillance of corruption, but no uniform reduction in corruption (Levin and Satarov, 2000). Moreover, a consensus has emerged around the role of historical legacies, social norms and culture could have in shedding light on cross-country differences in the prevalence of corruption (e.g. Becker et al., 2016). Here we thus propose to investigate the role of one cultural dimension: individualism in explaining the degree to which people are willing to act against corruption, in previously communist societies.

One reason that evidence on this relationship is missing is that previous empirical work uses country-level data and that the number of ex-communist countries is small. Recently though, the individualism-collectivism distinction has been studied at group (Kaasa et al., 2014) and individual level (e.g. Davis and Williamson, 2019). Thus, beyond the importance of culture as values held within a group, internalised individual values that are stable traits or a deep-rooted set of beliefs (Triandis, 2001), may explain differences in people's behaviours towards corruption. Tu et al. (2020) show that collectivist traits tend to be associated with a higher tolerance of public corruption because the penalty of being ostracised is higher than the benefit of acting ethically (Zheng et al., 2013). Collectivist values may also lower the likelihood to act against corruption (Tu, et al., 2020). But studies on this specific issue are limited to the Asian context (Gong and Xiao, 2017) and focus only on the responses of civil servants rather than the population as a whole (Tu et al., 2020). Existing individuallevel research on corruption in ex-communist countries has focussed on what determines paying bribes (Ivlevs and Hinks, 2015, 2018; Libman and Obydenkova, 2013) or the psychological cost of doing so (Amini and Douarin, 2020), rather than what it would take for people to act against it. In addition, none of these papers consider the role individualist or collectivist values can play in people's views towards bribery.

While in the traditional 'Homo Economicus' view, the decision to report a bribe depends on external factors, namely the costs and the reward from this specific action, psychology and institutional economics have shown that internal rewards also influence people's actions (e.g. Mazar and Ariely, 2006). Institutionalists have emphasised that the values internalised by individuals through socialisation will have a large impact on their decisions to adopt prosocial behaviours (Andriani and Sabatini, 2015; Irwin, 2009), or their willingness to embrace specific codes of conduct (Chen et al., 2007).

In this paper, we focus specifically on people's willingness to report corrupt activities and propose that individualism, as a set of internalised values promoting universalism and self-determination, will be positively related to one's willingness to report corruption. Indeed, firstly, individualism is characterised by self-expression, autonomy, self-determination and accomplishments. As well as impacting on the person themselves, these views can also impact on the wider society where individualism translates to meritocracy and individual potential' (Kyriacou, 2016: 100) while collectivism implies nepotism and clientelism which results in a higher likelihood of corruption. As a consequence of this, it is likely that people with individualistic views will report corruption. Second, individualism means that the cost of being excluded from a group is lower for more individualistic individuals meaning they are more likely to question and challenge in-group codes (Triandis, 2001). Indeed, Hofstede (2001) emphasises individualism as being associated with low conformity, and lower expectations of obedience. If some of these codes are deemed to be unethical, such as corruption, then individualistic people will be more likely to report corruption within these groups because the costs are far lower when compared to someone who holds collectivist views. This seems particularly relevant to the fight against corruption, as corruption is widely recognised as amoral or unfair even in populations where it is rife, but this recognition is not sufficient for corruption to abate (Rothstein, 2018) and something else is needed to challenge the status quo and address what might be a collective action problem. Accordingly, our first hypothesis is:

H1: Individualistic values are associated with a greater willingness to act against corruption. 
Although the focus of our analysis is on cultural dimensions, intended as a set of informal rules (see Alesina and Giuliano, 2015), it must be stressed that the way these translate into behaviours and preferences is inherently linked to formal institutions. Formal and informal institutions need to be compatible to lead to favourable economic outcomes (Boettke et al., 2008). Understanding the degree to which formal and informal institutions interact is thus key to understanding development. With this in mind, part of an individual's willingness to act against corruption will relate to how they perceive formal institutional quality, measured here as institutional trust. ${ }^{3}$ If trust in institutions is low, then individuals may think that people who act unlawfully are less likely to be caught, and if caught, less likely to be punished in a meaningful way. Individuals may then accept that unlawful acts are either normal, or cannot be addressed, given the weaknesses of the formal institutions. At the same time, some authors have suggested that in low social capital settings, citizens may ask for more state intervention, despite public corruption, as they might prefer imperfect state intervention, to private rent-seeking and its negative social externalities (Aghion et al., 2009). Indeed, in the postcommunist countries of Eastern Europe and Central Asia, both overall trust and trust in state institutions is low, but this has been shown empirically to be associated with more, not less, demand for state intervention (e.g. Denisova et al., 2010). This leads us to investigate the role of relative trust in state institutions, and gives rise to our second hypothesis:

H2: Greater relative (state) institutional trust will increase the reporting of corruption.

While relative institutional trust and individualism may independently impact on the willingness to act against corruption, as North (1990) argues, institutions do not act in isolation in shaping human behaviour. The interplay between institutional trust and individualism has already been shown to significantly affect individual's attitudes relating to interventionist preferences (Pitlik and Rode, 2017). Moreover, Irwin (2009) argues that variations in reported institutional trust explain why individuals in collectivist societies act in a prosocial manner, implying that institutional trust could compensate for collectivist values. An extension of these analyses is thus to test whether interacting individualism and institutional trust has any discernible impact on reporting corruption. For instance, $\mathrm{Tu}$ et al. (2020) documented that Chinese civil servants rejected corruption more if they believed the government's anti-corruption policies were effective, but this effect was dampened for those holding collectivist values. This implies that institutional trust channels individualistic value into specific attitudes and behaviours towards corruption. Accordingly, we posit that one's willingness to act against corruption in Eastern Europe and Central Asia will be greater for individualistic individuals but more so if they trust institutions to translate reporting into punishment.

H3: Higher relative institutional trust will positively moderate (strengthen) the relationship between individualistic values and the willingness to act against corruption.

\section{Data and measurements}

\subsection{Data source}

We use the third round of the Life in Transition Survey (LITS3), conducted between 2015 and 2016 by the World Bank and European Bank of Reconstruction and Development. The survey covers 34 countries of which 29 are post-communist countries. Our analysis focuses on these 29 countries only. In this survey, 1,500 households were interviewed in each country. The survey was designed by means of stratified clustered sampling with the sample stratified by geographical region and degree of urbanity. The primary respondent was selected randomly from all eligible respondents in each household.

\footnotetext{
${ }^{3}$ Institutional trust has been argued to reflect citizen's cumulative experience with public institutions (e.g. Gërxhani and Wintrobe, 2020).
} 


\subsection{Variables of interests}

\subsubsection{Acting against corruption}

We consider three survey questions that capture the degree to which people would be willing to report corruption if they were exposed to it, or how socially accepted they believe reporting corruption to be. None of the questions distinguish between public and private corruption. The first survey item: 'I Report' is based on the extent to which people agree with the statement 'If I would witness an act of corruption, I would feel personally obliged to report it'. Respondents are given five possible responses ranging from 1 (strongly disagree) to 5 (strongly agree). The second item: 'Court Report' is based on responses to the question 'I would report a case of corruption even if I would have to spend a day in court to give evidence' which takes values of 1 (strongly disagree) to 5 (strongly agree) and represents a stronger version of the 'I Report' question since it explicitly emphasises that the person would have to give up their time and speak publicly against another party. The third survey item is 'Acceptable Report' which measures on a 1 (strongly disagree) to 5 (strongly agree) scale the extent to which a respondent agrees with the statement 'In our society it is generally acceptable for people to report a case of corruption they witness'.

We use two additional variables relating to the degree to which a respondent thinks an ordinary citizen can do something in the face of corruption. Firstly, we create the variable 'Can_Do' which takes a value of 1 if the respondent believes ordinary people can do something to fight corruption such as refusing to pay bribes or protesting, and 0 if they think that 'ordinary people cannot do anything'. A second variable 'Ordinary_Diff is derived from a direct question on the strength of the belief that citizens are able to make a difference through the reporting of corruption. While 'Can-Do' refers to public corruption specifically, and most of the actions suggested reinforce this narrower focus of the question, 'Ordinary_Diff relates to a more generic form of 'corruption', which can be both public or private (Hodgson and Jiang, 2007). The latter is also true for our three other indicators, namely 'I Report', 'Court Report' and 'Acceptable Report'.

Figure 1 below reports the average scores by country for these five variables. The left-hand side axis is for 'Can-Do' (share of respondents believing something can be done), while all the other variables are scored against the right-hand side axis (average answer on a 1-5 scale). The countries are ordered by geographical localisation, starting with the Baltic states, the European Union Member states of Central, Eastern and South-Eastern Europe, the rest of the Balkans, and finally the former Soviet Union States - this ordering should thus approximate a decreasing level of institutional quality (Douarin and Mickiewicz, 2017). However, reporting of corruption appears as likely in Estonia (the least corrupt country in our sample in 2015 according to Transparency International, with a 'corruption perception index' or CPI of 70) than in Tajikistan for example (the most corrupt country, with a CPI of 26).

Accordingly, we recode all the variables that were measured on a scale of 1-5 into dummies equal to 1 if the respondent is indifferent, agrees or strongly agrees with reporting, and 0 otherwise. We are thus focusing on the drivers that can tip respondents towards being accepting of reporting. We will present below analyses based on linear probability models for ease of interpretation and to facilitate comparison across specification and outcomes ${ }^{4}$.

\subsubsection{Individualism}

To construct our measure of individualism/collectivism, we first identified 12 questions in the LITS3 survey relating closely to the values and beliefs that are known to be strongly associated with Hofstede's original concept. As noted repeatedly in the literature, Hofstede's individualism/collectivism concept relates to self-determination versus embeddedness in a given social group (e.g. Pitlik and Rode, 2017; Triandis, 2001). Individualistic people are expected to look after themselves, value personal success and take responsibility for their own decisions, while collectivist individuals will look

\footnotetext{
${ }^{4}$ We also conducted ordinal logit on the original-scale variables, and logit regressions using the transformed dummy variables. The results were qualitatively equivalent to the results we are presenting in the results section.
} 


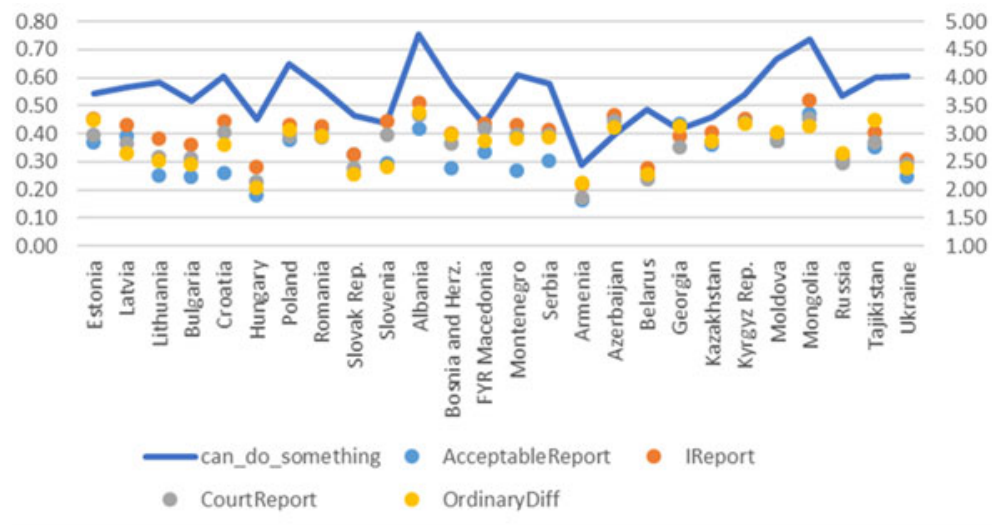

Figure 1. Average reporting by country.

after the interest of a narrowly defined reference group, will value conformity and abiding by traditions.

Accordingly, we include survey items that capture the fact that individualism is characterised by a focus on personal freedom and achievement and social status depends on personal accomplishment (Gorodnichenko and Roland, 2017). In the spirit of Schwartz (1994) and Schwartz and Bardi (2001), we thus include questions asking if those who are struggling are lazy and if effort and hard work are important for success. In addition, individualism is associated with greater preferences for competition and market capitalism (Beugelsdijk et al., 2015; Oyserman et al., 2002), so we include survey items regarding whether competition is good or harmful and whether people prefer private or government ownership. Finally, in individualistic society, inequality may be accepted as a natural outcome of individual differences and motivations (Fevre, 2016; Singelis et al., 1995), while redistribution can be seen as interference, we thus include questions relating to the acceptability of inequality and tax paying (Hammar, 2020).

To capture embeddedness in a given social group, we include several survey items relating to conformity and adopting traditional values. Thus, we include two survey questions (if co-habiting couples should be married and tolerance towards homosexuality) that relate to attitudes towards nonconformity, and tolerance for personal freedom. Following Schwartz (1994) and Schwartz and Bardi (2001), we also include questions on whether women should stay at home, if men are better political leaders and equality of men and women regarding the distribution of household chores. These inclusions are further supported by recent evidence on the positive association between individualism and support for gender equality (Davis and Williamson, 2019). Finally, individuals in collective societies tend to favour members in their own group, and to do so they may be more willing to violate the law (Achim, 2016; Banfield, 1958; Jha and Panda, 2017), hence we include a question on the importance of abiding by the law. Overall, these questions reflect the extent to which individuals tend to follow their own preferences over what has been set by tradition, family expectation and social norms (Beugelsdijk et al., 2015; Hofstede, 2001).

On the basis of these 12 items, we then ran a polychoric Principal Component Analysis (PCA) on all the variables allowing us to extract four components that captured meaningful latent 'meta concepts' in our set of variables (Hair et al., 2014). We then constructed four sub-sets of variables matching these four components including only the variables with factor loadings $>0.3$ and for which the Cronbach $\alpha$ was optimised (in keeping with Beugelsdijk et al., 2015). We ran four new polychoric PCAs on these four sub-sets of variables, and kept as our measure of individualism the only component extracted from these which charged the constitutive variables in a way that is consistent with Hofstede's definition of individualism. Employing this statistical technique allows us to create a 
composite indicator reflecting a latent unidimensional concept in the data that is consistent with Hofstede's definition. That is to say that we have created a data-driven measure of individualism, which is conceptually sound, rather than adopting arbitrarily a measure developed in a different survey and on a different sample.

Our final measure is as follows ${ }^{5}$ :

$$
\begin{aligned}
\text { Individualism }= & 0.73 * \text { preferences towards income inequality over equality } \\
& -0.30 * \text { preference for public ownership over private ownership } \\
& -0.68 * \text { intolerance towards homosexuality }
\end{aligned}
$$

Our final measure is thus the weighted sum of the respondent's view on three dimensions, namely tolerance for inequality, preferences for public and private ownership and tolerance towards homosexuality. It is closely aligned with the measure derived by Beugelsdijk et al. (2015) using an analogous methodology, but using a different survey and sample, as their individualism/collectivism variable includes preference for public/private ownership and tolerance towards homosexuality too. In addition, a negative association between individualism and preferences for redistribution is strongly supported by Hammar (2020). As a result of the statistical procedure employed, we do not consider the other dimensions in our remaining analyses. We note that to the best of our knowledge, this constitutes a first attempt at constructing indices to capture cultural dimensions according to Hofstede using LITS3.

\subsubsection{Institutional trust}

In the survey, respondents rated their trust in different institutions (public or not) on a scale of 1 (complete distrust) to 5 (complete trust). We created our measure of institutional trust by computing the average level of trust in a set of public institutions (namely: president, central government, local government, political parties, parliaments and the courts). The raw average for this trust variable over the full sample investigated is 2.7 , reflecting on the low level of trust in state institutions in the region overall. The raw average for state institutions and non-state institutions together (so also including trust in NGOs, banks, foreign investors, trade unions or religious institutions) is slightly greater at 2.85. To account for the "kvetch effect' ${ }^{6}$ and because relative trust is likely to be more meaningful in this low trust context (Denisova et al., 2010), we follow Hudson (2006) and calculate relative trust in institutions by dividing the average trust in public institutions by the average trust in all institutions (both state and non-state institutions) included in the survey questionnaire.

\subsubsection{Other controls}

In addition, we employ a rich set of controls, both to reflect standard specification in the literature, and to reduce omitted variable bias. Indeed, studies focusing on the relationship between formal and informal institutions may suffer from endogeneity issues due to reverse causality or omitted variable bias (Alesina and Giuliano, 2015). Reverse causality in our paper would imply that being willing to act against corruption can impact on someone's individualistic values. This is unlikely since individual values (individualistic or collectivist) change slowly over time, and while the LITS survey captures values, and thus individualism, today, it probes on the willingness to report corruption in the future, making reverse causality incompatible with the chronology of events. To address the problem of omitted variable bias, we include socio-economic controls for age, education, household income, gender, marital status, perceived health and an urban dummy. This first set of variables represents tangible controls, and excludes variables capturing values which could be correlated with individualism or trust. This allows us to illustrate the associations between our variables of interest while minimising bias due to multi-collinearity between our controls. In additional analyses, we complemented our

\footnotetext{
${ }^{5} \mathrm{We}$ note that this measure of individualism is thus quite similar to the one advanced in Beugelsdijk et al. (2015).
} 
controls to test the robustness of our findings: we added controls for religious affiliation (as potentially capturing cultural differences), preference towards risk and two controls for the perceived importance of corruption. The first of these reflects whether the respondent picked corruption as being one of the three (out of 10) most important problems faced by their country of residence. The second indicator captures the perceived breadth of corruption, and is based on responses to how corrupt people think nine categories of public figures (including business leaders, religious leaders and a variety of public officials) are. These results are not reported in the paper (but are available upon request) but they confirm our main findings, thus mitigating the risk that our findings are driven by omitted variables, while illustrating that multi-collinearity is not a major issue for our conclusions.

The descriptive statistics for our variables can be found in Table A1 in Appendix.

\section{Results}

\subsection{Estimations: direct effects}

In a first set of estimations, we focus on the relationship between individualism, relative institutional trust and different measures of corruption reporting, using a parsimonious model, including only controls capturing the key socio-economic characteristic of the respondents. Namely, we control for household income (ln), age, gender, educational achievement, marital status (married, single or divorced/ widowed, with the last one being our reference category) and a subjective measure of poor health. With these models, we assess the extent to which individualism and relative institutional trust correlate to corruption reporting, individually, and in a horse race, so as to test our hypotheses 1 and 2.

Table 1 focuses on our three preferred variables of interest, capturing people's willingness to act against corruption: i.e. reporting corruption, even if it means having to go to court, believing ordinary people can make a difference by reporting corruption and stating that it is socially acceptable to report corruption. In all cases, we find that education is positively correlated with expressing positive views on reporting, while poor health is negatively correlated with it. Female respondents and respondents with a larger household income are also more likely to be willing to report corruption, even if they need to go to court, and to think that ordinary people can make a difference, while older respondents are less likely to be willing to report corruption or to think ordinary people can make a difference. Gender, income and age are however not significantly correlated to how socially acceptable the respondent thinks it is to report corruption.

Regarding individualism and relative institutional trust, our estimates reveal that both are positively associated with expressing support for reporting corruption, and these associations are confirmed in our horse-race specification too. In all cases, including both individualism and relative institutional trust improves the fit of the model, and the coefficient estimated for these two variables appears very stable, indicating that correlations reported do not suffer significantly from collinearity issues. Even though the coefficient reported for relative institutional trust is generally larger, the smaller standard deviation for this variable means that the association between our reporting variables and both individualism and relative institutional trust is of comparable magnitude. For example, an increase by 1 standard deviation in individualism is associated with a 2.8 percentage point greater likelihood to think reporting corruption is socially acceptable, while an increase by 1 standard deviation in relative institutional trust is associated with a 2.2 percentage point greater likelihood to believe reporting corruption is socially acceptable. Similarly, an increase by 1 standard deviation in individualism is associated with a 1.2 percentage point greater likelihood to state being willing to report corruption even if it means spending a day in court, while an increase by 1 standard deviation in relative institutional trust is associated with a 1.4 percentage point greater likelihood to be willing to report corruption at the cost of spending a day in court. While these associations might seem small, they are not negligible in a context where less than half of our respondents actually report supporting corruption reporting.

Using the same specifications, we also use two alternative measures of support for reporting corruption: namely believing citizen can do something against public corruption (i.e. focusing on a narrower definition of corruption) or stating a personal willingness to report corruption, but in a question 
Table 1. Determinants of corruption reporting (main outcome variables)

\begin{tabular}{|c|c|c|c|c|c|c|c|c|c|}
\hline & (1) & (2) & (3) & (4) & (5) & (6) & (7) & (8) & (9) \\
\hline Variables & \multicolumn{3}{|c|}{ Ordinary difference } & \multicolumn{3}{|c|}{ Court report } & \multicolumn{3}{|c|}{ Acceptable report } \\
\hline \multirow[t]{2}{*}{ Individualism } & $0.012^{\star \star \star}$ & $0.012^{\star \star \star}$ & & $0.005^{\star \star}$ & $0.005^{\star \star}$ & & $0.012^{\star \star \star}$ & $0.012^{\star \star \star}$ & \\
\hline & $(0.002)$ & $(0.002)$ & & $(0.002)$ & $(0.002)$ & & $(0.002)$ & $(0.002)$ & \\
\hline \multirow{2}{*}{ Relative inst., trust } & $0.130^{\star \star \star}$ & & $0.129^{\star \star \star}$ & $0.081^{\star \star \star}$ & & $0.080^{\star \star \star}$ & $0.173^{\star \star \star}$ & & $0.172^{\star \star \star}$ \\
\hline & $(0.028)$ & & $(0.028)$ & $(0.028)$ & & $(0.028)$ & $(0.028)$ & & $(0.028)$ \\
\hline \multirow[t]{2}{*}{ Hh income (In) } & $0.019^{\star \star}$ & $0.018^{\star \star}$ & $0.020^{\star \star}$ & $0.020^{\star \star \star}$ & $0.020^{\star \star}$ & $0.021^{\star \star \star}$ & -0.004 & -0.004 & -0.002 \\
\hline & $(0.008)$ & $(0.008)$ & $(0.008)$ & $(0.008)$ & $(0.008)$ & $(0.008)$ & $(0.005)$ & $(0.005)$ & $(0.005)$ \\
\hline \multirow[t]{2}{*}{ Education (years) } & $0.004^{\star \star \star}$ & $0.004^{\star \star \star}$ & $0.005^{\star \star \star}$ & $0.003^{\star \star}$ & $0.003^{\star \star}$ & $0.003^{\star \star}$ & $-0.005^{\star \star \star}$ & $-0.005^{\star \star \star}$ & $-0.004^{\star \star \star}$ \\
\hline & $(0.001)$ & $(0.001)$ & $(0.001)$ & $(0.001)$ & $(0.001)$ & $(0.001)$ & $(0.001)$ & $(0.001)$ & $(0.001)$ \\
\hline \multirow[t]{2}{*}{ Poor health } & $-0.059^{\star \star \star}$ & $-0.061^{\star \star \star}$ & $-0.061^{\star \star \star}$ & $-0.057^{\star \star \star}$ & $-0.058^{\star \star \star}$ & $-0.058^{\star \star \star}$ & $-0.064^{\star \star \star}$ & $-0.066^{\star \star \star}$ & $-0.066^{\star \star \star}$ \\
\hline & $(0.012)$ & $(0.012)$ & $(0.012)$ & $(0.012)$ & $(0.012)$ & $(0.012)$ & $(0.012)$ & $(0.012)$ & $(0.012)$ \\
\hline \multirow[t]{2}{*}{ Urban } & 0.002 & 0.004 & 0.001 & 0.012 & 0.013 & 0.012 & 0.017 & 0.019 & 0.016 \\
\hline & $(0.014)$ & $(0.014)$ & $(0.014)$ & $(0.014)$ & $(0.014)$ & $(0.014)$ & $(0.014)$ & $(0.014)$ & $(0.014)$ \\
\hline \multicolumn{10}{|c|}{ Marital status (ref. divorced, widowed) } \\
\hline \multirow[t]{2}{*}{ Single } & -0.002 & -0.002 & -0.002 & 0.015 & 0.016 & 0.016 & $0.022^{\star}$ & $0.023^{\star}$ & $0.023^{\star}$ \\
\hline & $(0.012)$ & $(0.012)$ & $(0.012)$ & $(0.013)$ & $(0.014)$ & $(0.013)$ & $(0.013)$ & $(0.013)$ & $(0.013)$ \\
\hline \multirow[t]{2}{*}{ Married } & -0.007 & -0.007 & -0.007 & 0.002 & 0.002 & 0.002 & -0.004 & -0.004 & -0.004 \\
\hline & $(0.010)$ & $(0.010)$ & $(0.010)$ & $(0.011)$ & $(0.011)$ & $(0.011)$ & $(0.010)$ & $(0.010)$ & $(0.010)$ \\
\hline \multirow[t]{2}{*}{ Age } & $-0.001^{\star \star \star}$ & $-0.001^{\star \star}$ & $-0.001^{\star \star \star}$ & $-0.001^{\star \star \star}$ & $-0.001^{\star \star \star}$ & $-0.001^{\star \star \star}$ & 0.000 & 0.000 & 0.000 \\
\hline & $(0.000)$ & $(0.000)$ & $(0.000)$ & $(0.000)$ & $(0.000)$ & $(0.000)$ & $(0.000)$ & $(0.000)$ & $(0.000)$ \\
\hline \multirow[t]{2}{*}{ Gender } & $0.015^{\star \star}$ & $0.015^{\star}$ & $0.016^{\star \star}$ & $0.020^{\star \star \star}$ & $0.020^{\star \star \star}$ & $0.021^{\star \star \star}$ & 0.002 & 0.002 & 0.003 \\
\hline & $(0.007)$ & $(0.007)$ & $(0.007)$ & $(0.007)$ & $(0.007)$ & $(0.007)$ & $(0.007)$ & $(0.007)$ & $(0.007)$ \\
\hline \multirow[t]{2}{*}{ Constant } & $0.311^{\star \star \star}$ & $0.434^{\star \star \star}$ & $0.321^{\star \star \star}$ & $0.347^{\star \star \star}$ & $0.423^{\star \star \star}$ & $0.351^{\star \star \star}$ & $0.508^{\star \star \star}$ & $0.672^{\star \star \star}$ & $0.518^{\star \star \star}$ \\
\hline & $(0.108)$ & $(0.105)$ & $(0.110)$ & $(0.108)$ & $(0.105)$ & $(0.109)$ & $(0.076)$ & $(0.071)$ & $(0.077)$ \\
\hline Observations & 19,888 & 19,888 & 19,888 & 19,443 & 19,443 & 19,443 & 19,860 & 19,860 & 19,860 \\
\hline$R^{2}$ & 0.079 & 0.078 & 0.077 & 0.072 & 0.071 & 0.071 & 0.110 & 0.107 & 0.107 \\
\hline Country FE & Yes & Yes & Yes & Yes & Yes & Yes & Yes & Yes & Yes \\
\hline
\end{tabular}


Table 2. Determinants of corruption reporting (alternative outcome variables)

\begin{tabular}{|c|c|c|c|c|c|c|}
\hline & (1) & (2) & (3) & (4) & (5) & (6) \\
\hline Variables & & can_doR & & & IReportDR & \\
\hline \multirow[t]{2}{*}{ Individualism } & $0.009^{\star \star \star}$ & $0.009^{\star \star \star}$ & & $0.004^{\star \star}$ & $0.004^{\star \star}$ & \\
\hline & $(0.002)$ & $(0.002)$ & & $(0.002)$ & $(0.002)$ & \\
\hline \multirow[t]{2}{*}{ Relative inst., trust } & $0.107^{\star \star \star}$ & & $0.106^{\star \star \star}$ & $0.049^{*}$ & & $0.048^{*}$ \\
\hline & $(0.028)$ & & $(0.028)$ & $(0.027)$ & & $(0.027)$ \\
\hline \multirow[t]{2}{*}{ Hh income (In) } & $0.011^{\star \star}$ & $0.011^{\star \star}$ & $0.012^{\star \star}$ & $0.009^{\star \star}$ & $0.009^{\star *}$ & $0.010^{* *}$ \\
\hline & $(0.005)$ & $(0.005)$ & $(0.005)$ & $(0.004)$ & $(0.004)$ & $(0.004)$ \\
\hline \multirow[t]{2}{*}{ Education (years) } & $0.011^{\star \star \star}$ & $0.011^{\star \star \star}$ & $0.012^{\star \star \star}$ & $0.007^{\star \star \star}$ & $0.007^{\star \star \star}$ & $0.007^{\star * \star}$ \\
\hline & $(0.001)$ & $(0.001)$ & $(0.001)$ & $(0.001)$ & $(0.001)$ & $(0.001)$ \\
\hline \multirow[t]{2}{*}{ Poor health } & $-0.039^{\star \star \star}$ & $-0.040^{\star \star \star}$ & $-0.041^{\star \star \star}$ & $-0.076^{\star \star \star}$ & $-0.077^{\star \star \star}$ & $-0.077^{\star \star \star}$ \\
\hline & $(0.012)$ & $(0.012)$ & $(0.012)$ & $(0.012)$ & $(0.012)$ & $(0.012)$ \\
\hline \multirow[t]{2}{*}{ Urban } & -0.015 & -0.014 & -0.017 & 0.000 & 0.001 & -0.000 \\
\hline & $(0.014)$ & $(0.014)$ & (0.014) & $(0.013)$ & $(0.013)$ & $(0.013)$ \\
\hline \multicolumn{7}{|c|}{ Marital status (ref. divorced, widowed) } \\
\hline \multirow[t]{2}{*}{ Single } & -0.007 & -0.007 & -0.007 & 0.015 & 0.015 & 0.015 \\
\hline & $(0.012)$ & $(0.013)$ & $(0.012)$ & $(0.012)$ & $(0.012)$ & $(0.012)$ \\
\hline \multirow[t]{2}{*}{ Married } & 0.010 & 0.010 & 0.010 & 0.000 & 0.000 & 0.000 \\
\hline & $(0.010)$ & $(0.010)$ & $(0.010)$ & $(0.010)$ & $(0.010)$ & $(0.010)$ \\
\hline \multirow[t]{2}{*}{ Age } & $-0.001^{\star \star \star}$ & $-0.001^{\star \star \star}$ & $-0.001^{\star \star \star}$ & $-0.001^{\star \star}$ & $-0.001^{\star \star}$ & $-0.001^{\star \star}$ \\
\hline & $(0.000)$ & $(0.000)$ & $(0.000)$ & $(0.000)$ & $(0.000)$ & $(0.000)$ \\
\hline \multirow[t]{2}{*}{ Gender } & $0.029^{\star \star \star}$ & $0.029^{\star \star \star}$ & $0.029^{\star \star \star}$ & 0.011 & 0.011 & 0.011 \\
\hline & $(0.007)$ & $(0.007)$ & $(0.007)$ & $(0.007)$ & $(0.007)$ & $(0.007)$ \\
\hline \multirow[t]{2}{*}{ Constant } & $0.418^{\star \star \star}$ & $0.520^{\star \star \star}$ & $0.426^{\star \star \star}$ & $0.552^{\star \star \star}$ & $0.598^{\star \star \star}$ & $0.555^{\star \star \star}$ \\
\hline & $(0.071)$ & $(0.069)$ & $(0.071)$ & $(0.063)$ & $(0.060)$ & $(0.063)$ \\
\hline Observations & 21,188 & 21,188 & 21,188 & 19,554 & 19,554 & 19,554 \\
\hline$R^{2}$ & 0.082 & 0.081 & 0.080 & 0.073 & 0.073 & 0.073 \\
\hline Country FE & Yes & Yes & Yes & Yes & Yes & Yes \\
\hline
\end{tabular}

Robust standard errors in parentheses.

${ }^{\star \star \star} p<0.01,{ }^{\star \star} p<0.05,{ }^{*} p<0.1$.

that does not explicitly quantify the potential cost of reporting. These results are reported in Table 2 . In the case of the personal willingness to report corruption without factoring in the possibility of spending a day in court, relative institutional trust appears much less significant, and with a smaller coefficient, than when that cost is made explicit in the question, which is in line with expectations.

In results not reported here, but available upon request, we also tested the association between individualism, relative institutional trust and support for reporting corruption including a number of additional controls. While on the one hand, these additions can increase our confidence in the robustness of our findings and can suggest that the relations identified are not due to omitted variable bias, they can also create spurious results due to multi-collinearity. As our results however remain completely stable with these additions, we can credibly say that the latter can only be a minor concern in our case. In these regressions, we include religious affiliation (as potentially capturing cultural differences), preference towards risk, and two controls for the perceived importance of corruption. These (relatively over-specified) regressions thus help us confirm that both individualism and institutional trust matter 
Table 3. Interactions terms with specification tests

\begin{tabular}{|c|c|c|c|c|c|}
\hline & (1) & (2) & (3) & (4) & (5) \\
\hline Variables & OrdinaryDiffD & CourtreportDR & AccReportDR & can_doR & IReportDR \\
\hline \multirow[t]{2}{*}{ Individualism } & -0.010 & $-0.015^{\star}$ & -0.005 & -0.008 & $-0.017^{\star}$ \\
\hline & $(0.009)$ & $(0.009)$ & $(0.009)$ & (0.009) & $(0.009)$ \\
\hline \multirow[t]{2}{*}{ Rel. inst. trust } & 0.056 & 0.014 & $0.116^{\star \star \star}$ & 0.050 & -0.022 \\
\hline & $(0.042)$ & $(0.042)$ & $(0.041)$ & $(0.041)$ & $(0.040)$ \\
\hline \multirow[t]{2}{*}{ Interaction term } & $0.024^{\star \star}$ & $0.022^{\star \star}$ & $0.019^{\star}$ & $0.019^{\star \star}$ & $0.023^{\star \star}$ \\
\hline & $(0.010)$ & $(0.010)$ & $(0.010)$ & (0.009) & $(0.009)$ \\
\hline Controls & Yes & Yes & Yes & Yes & Yes \\
\hline Country FE & Yes & Yes & Yes & Yes & Yes \\
\hline Observations & 19,888 & 19,443 & 19,860 & 21,188 & 19,554 \\
\hline$R^{2}$ & 0.080 & 0.072 & 0.110 & 0.082 & 0.074 \\
\hline Specification test ( $F$-test) & $F(1,1879)$ & $F(1,1879)$ & $F(1,1877)$ & $F(1,1958)$ & $F(1,1880)$ \\
\hline Adding interaction term & $5.59^{\star \star}$ & $5.07^{\star \star}$ & $3.60^{*}$ & $3.91^{\star \star}$ & $6.05^{\star \star}$ \\
\hline
\end{tabular}

Controls as in Tables 1 and 2.

Robust standard errors in parentheses.

${ }^{* * *} p<0.01,{ }^{* *} p<0.05,{ }^{*} p<0.1$.

individually for corruption reporting, and that they matter over and above other variables capturing the values and beliefs of the respondents.

\subsection{Interaction terms}

To test our third hypothesis, we added an interaction term between individualism and relative institutional trust, to identify whether these two variables could present some complementarities in their relationship with corruption reporting. We thus replicated the horse race specifications presented in Tables 1 and 2 (specifically models 1,4 and 7 in Table 1 and models 1 and 4 in Table 2) with an additional interaction term, and the results are presented in Table 3. As shown by the $F$ test reported, in all cases the addition of an interaction term does improve the fit of the model and the interactions appear positive and significant, suggesting a complementarity between individualism and relative institutional trust. It is worth clarifying here how we interpret the impact of individualism once the interaction is included in the model. If $\widehat{\beta_{1}}$ is the estimated parameter for individualism and $\widehat{\beta_{2}}$ the equivalent parameter for the interaction term, then the impact of individualism on the outcome variables is conditional on the level of trust, so it should be calculated as $\widehat{\beta_{1}}+\widehat{\beta_{2}}$ (trust). It is quite typical to calculate such an impact at the mean value of the variable involved in the interaction. In this case, the impact of individualism on 'ordinary difference' is 0.03 at the mean level of institutional trust and increases to 0.05 when relative trust reaches the maximum value of 1.76 .

We also present these effects in graphical form in Figure 2. In all cases, we can see that the marginal effects of individualism on our different corruption reporting measures are positive and increasing with relative institutional trust, that is to say individualistic individuals are more likely to report corruption, to state they believe reporting corruption is socially acceptable or to believe ordinary people can make a difference against corruption, if they have greater relative institutional trust. In fact, at low levels of relative institutional trust, holding individualistic values is not associated with a greater likelihood of reporting corruption if it means spending some time in court, for this variable, individualism will only be associated with more reporting if the respondent has more than a median level of relative 
Figure 2. Marginal effects graphs.

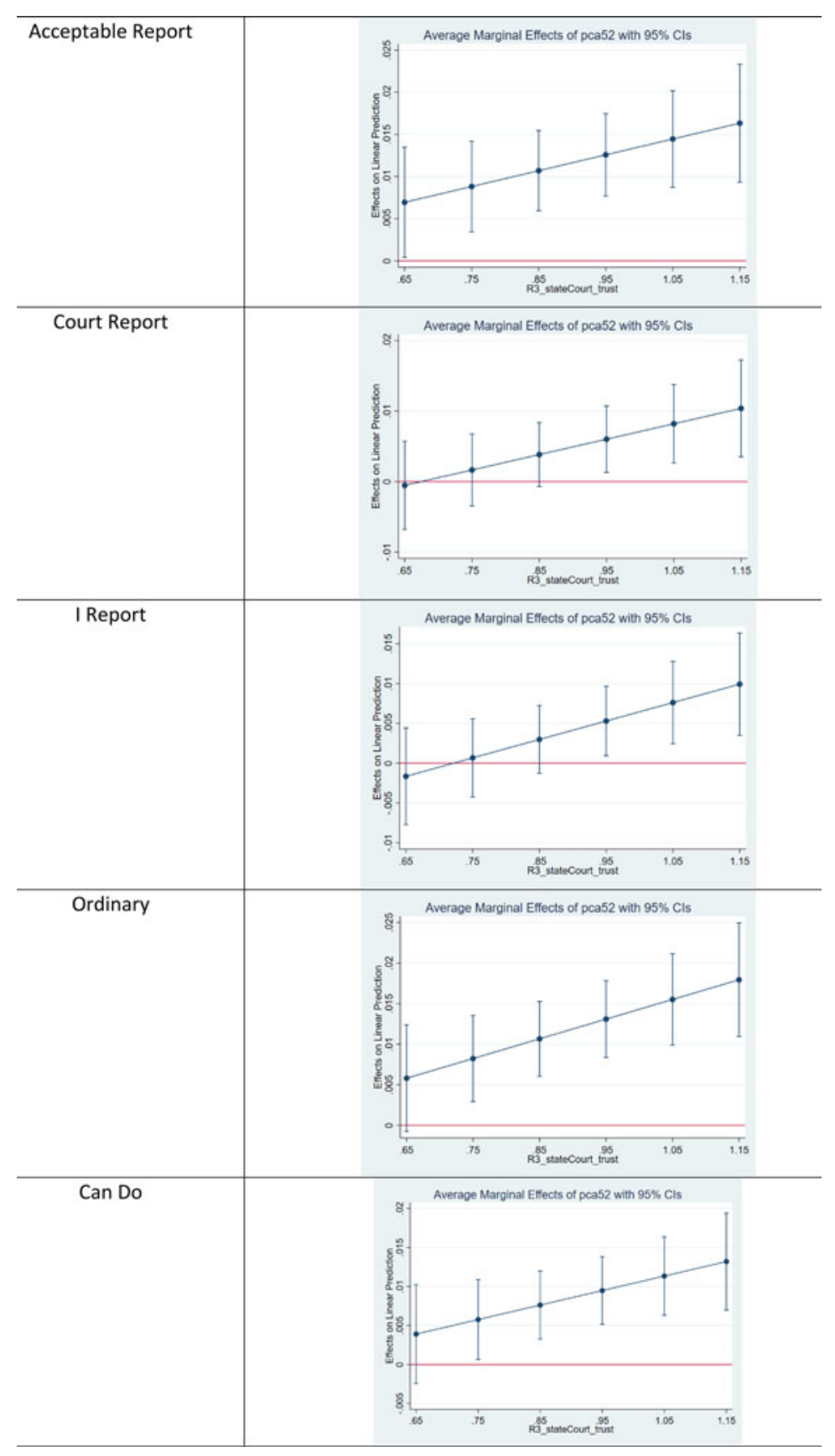

institutional trust. Similarly, for believing that ordinary people can make a difference, individualism will only be associated with greater belief if relative institutional trust is above the $10^{\text {th }}$ percentile for the estimation sample. Finally, individualism is significantly and positively associated with believing that reporting is socially acceptable, even at low levels of institutional trust; however, for those in the top $10^{\text {th }}$ percentile of the trust distribution, the impact of individualistic values is three times greater than for respondents in the bottom $10^{\text {th }}$ percentile. 


\section{Discussion and conclusions}

The incidence and tolerance towards corruption have been shown to be partly explained by cultural values either measured at the country-level (e.g. Achim, 2016) or at the individual level (Zheng et al., 2013). Here, we expand on these findings by looking into people's willingness to report corruption in a large cross-national survey. We find a consistent positive association between individualism and the likelihood of reporting corruption, the belief that others will report it and the notion that ordinary citizens can do something to tackle corruption. This is true when we control for religiosity, attitudes towards risk, perceptions of the importance and breadth of corruption as well as other socio-economic factors. We also find a positive correlation between relative institutional trust on all these anti-corruption variables. Interaction terms further indicate that the direct effect of individualism is moderated somewhat by institutional trust. Overall, individualism is more likely to be positively associated with citizens' willingness to engage in anti-corruption actions, amongst those who have greater relative trust in (state) institutions.

Compatible results have been documented elsewhere. For example, in a study focusing on a collectivist society with low institutional capacity, Andriani and Sabatini (2015) concluded that low institutional trust could compromise social order by reducing the degree to which individuals were willing to adopt pro-social behaviours. Our study expands on their general results by demonstrating that individualistic values can interact with relative institutional trust in their association with specific behaviours. In our sample of post-communist countries, we find that individualistic values do correlate with more pro-social behaviours but especially so when accompanied by higher levels of relative institutional trust.

By relying on a micro-level analysis of the inter-play of culture and institutions, our results highlight why similar policy interventions can lead to divergent outcomes in different contexts. Kimenyi (2011) argues that such a micro-focus is key to understanding changing social interactions and thus the true impact of institutions. Building on our results, we can posit that interventions trying to facilitate corruption reporting (e.g. anonymised reporting online) are likely to be ineffective in a context of low institutional trust, and generally much less effective on strongly collectivist individuals compared to individualistic ones. Similarly, if societies have become increasingly individualistic (as evidenced, for example, in Beugelsdijk et al., 2015; Hamamura, 2012), our results suggest that not all of them will have experienced a commensurate reduction in corruption, at least partly because attitudes towards corruption may have changed differentially depending on the prevalent level of institutional trust.

Individualistic people are less likely to conform to informal norms, as well as being less tolerant towards unfairness (Dungan et al., 2014). Individualistic values have also been argued to support growth and development (Mokyr, 1990). The evidence presented here suggests that such values might contribute to challenging the status quo, as they are associated with greater willingness to act against corruption. A key policy-relevant implication of our analysis is that anti-corruption measures are more likely to be effective where individualistic values are widespread, and where there is some degree of institutional trust. Our findings also seem particularly important in the context of bottom-up approaches that rely on active participation of citizens. Many governments in recent time have tried to augment the capacities and/or uptake interventions of ICT-enabled approaches to tackle corruption ${ }^{6}$. Part of these strategies is based around the development of online platforms that can be used to anonymously and voluntarily report bribes online and as such they rely heavily on individual willingness to act against corruption. In spite of the potential of these interventions, little is known about the factors that affect the demand, hence the use, of these tools. Our research points out that individual values and institutional trust matter in understanding one's willingness to act against corruption, hence we believe that future research on corruption should consider citizen values and beliefs.

\footnotetext{
${ }^{6}$ Weaver (2015) finds that a greater use of e-government allows citizen to report bribe offerings in a safe and confidential way, and thus helps increase the reporting of corruption. In Ukraine, for example, the e-platform ProZorro has boosted transparency and competition in public procurement since being implemented in 2016 and has saved an estimated \$2 bn in state procurement expenditures (Lough and Dubrovskiy, 2018).
} 


\section{References}

Achim, M. (2016), 'Cultural Dimension of Corruption: A Cross-Country Survey', International Advances in Economic Research, 22(3): 333-345.

Aghion, P., Y. Algan, P. Cahuc and A. Shleifer (2009). 'Regulation and Distrust', NBER Working Paper No. 14648, Cambridge, MA: National Bureau of Economic Research.

Alesina, A. and P. Giuliano (2015), 'Culture and Institutions', Journal of Economic Literature, 53(4): 898-944.

Amini, C. and E. Douarin (2020), 'Corruption and Life Satisfaction in Transition: Is Corruption a Social Norm in Eastern Europe?', Social Indicators Research, 151(2): 723-766.

Andriani, L. and F. Sabatini (2015), 'Trust and Prosocial Behaviour in a Process of State Capacity Building: The Case of the Palestinian Territories', Journal of Institutional Economics, 11(4): 823-846.

Banfield, E. (1958), Moral Basis of a Backward Society, Glencoe, Ill.: Free Press - Chicago. Research Center in Economic Development and Cultural Change, University of Chicago.

Becker, S., K. Boeckh, C. Hainz and L. Woessmann (2016), 'The Empire is Dead, Long Live the Empire! Long-Run Persistence of Trust and Corruption in the Bureaucracy', The Economic Journal, 126(590): 40-74.

Beugelsdijk, S., R. Maseland and A. van Hoorn (2015), 'Are Scores on Hofstede's Dimensions Stable Over Time?', Global Strategy Journal, 5(3): 223-240.

Boettke, P. J., C. J. Coyne and P. T. Leeson (2008), 'Institutional Stickiness and the New Development Economics', American Journal of Economics and Sociology, 67(2): 331-358.

Chen, X. P., S. A. Wasti and H. C. Triandis (2007), 'When Does Group Norm or Group Identity Predict Cooperation in a Public Goods Dilemma? The Moderating Effects of Idiocentrism and Allocentrism', International Journal of Intercultural Relations, 31(2): 259-276.

Davis, L. and C. Williamson (2019), 'Does Individualism Promote Gender Equality?', World Development, 123(November): 104627.

Denisova, I., M. Eller and E. Zhuravskaya (2010), 'What do Russians Think About Transition?', Economics of Transition, 18 (2): 249-280.

Douarin, E. and T. Mickiewicz (2017) Economics of Institutional Change - Central and Eastern Europe Revisited, Basingstoke: Palgrave Macmillan.

Dungan, J., A. Waytz and L. Young (2014), 'Corruption in the Context of Moral Trade-Offs', Journal of Interdisciplinary Economics, 26(1-2): 97-118.

EBRD (2019), Better Governance, Better Economies. Transition Report 2019-20, London: European Bank for Reconstruction and Development.

Fevre, R. (2016), Individualism and Inequality: The Future of Work and Politics, Cheltenham, UK: Edward Elgar.

Fukuyama, F. (2011), The Origins of Political Order. From Pre-Human Times to the French Revolution, London: Profile Books.

Fukuyama, F. (2014), Political Order and Political Decay. From the Industrial Revolution to the Globalization of Democracy, New York: Farrar, Straus and Giroux.

Gërxhani, K. and R. Wintrobe (2020), 'Understanding Tax Evasion: Combining the Public Choice and New Institutionalist Perspectives', in The Palgrave Handbook of Comparative Economics, Douarin, E. and O. Havrylyshyn (Editors). Springer Nature Switzerland AG, pp.785-810.

Gong, T. and H. Xiao (2017), 'Socially Embedded Anti-Corruption Governance: Evidence from Hong Kong', Public Administration and Development, 37(3): 176-190.

Gorodnichenko, Y. and G. Roland (2011), 'Which Dimensions of Culture Matter for Long-run Growth?', American Economic Review Papers and Proceedings, 101(3): 492-498.

Gorodnichenko, Y. and G. Roland (2012), 'Understanding the Individualism-Collectivism Cleavage and Its Effects: Lessons from Cultural Psychology', in M. Aoki, T. Kuran, and G. Roland (eds), Institutions and Comparative Economic Development. International Economic Association Series. London: Palgrave Macmillan, pp.213-236.

Gorodnichenko, Y. and G. Roland (2017), 'Culture, Institutions, and the Wealth of Nations', The Review of Economics and Statistics, 99(3): 402-416.

Guiso, L., P. Sapienza and L. Zingales (2006), 'Does Culture Affect Economic Outcomes?', Journal of Economic Perspectives, 20(2): 23-48.

Hair, J., W. Black, B. J. Babin and R. Anderson (2014), Multivariate Data Analysis Seventh Edition, Harlow: Pearson.

Hamamura, T. (2012), 'Are Cultures Becoming Individualistic? A Cross-Temporal Comparison of Individualism-Collectivism in the United States and Japan', Personality and Social Psychology Review, 16(1): 3-24.

Hammar, O (2020), The Cultural Assimilation of Individualism and Preferences for Redistribution, Mimeo, November 9th, 2020.

Havrylyshyn, O. (2020), Present at the Transition. An Inside Look at the Role of History, Politics, and Personalities in Post-Communist Countries, Cambridge University Press.

Heine, S.J. (2007), Cultural Psychology, New York: Norton \& Company.

Hodgson, G. and S. Jiang (2007), 'The Economics of Corruption and the Corruption of Economics: An Institutionalist Perspective', Journal of Economic Issues, 41(4): 1043-1061. 
Hofstede, G. (1991), Cultures and Organizations: Software of the Mind, New York, NY: McGraw-Hill.

Hofstede, G. (2001), Culture's Consequences: Comparing Values, Behaviors, Institutions, and Organizations Across Nations, Thousand Oaks, CA: SAGE.

Hofstede, G., G. J. Hofstede and M. Minkov (2010), Cultures and Organizations: Software of the Mind (3rd edn), New York: McGraw-Hill.

Hudson, J. (2006), 'Institutional Trust and Subjective Well-Being Across the EU', Kyklos, 59(1): 43-62.

Irwin, K. (2009), 'Prosocial Behavior Across Cultures: The Effects of Institutional Versus Generalized trust', in Shane R. Thye, and Edward J. Lawler (ed.), Altruism and Prosocial Behavior in Groups Advances in Group Processes (Vol. 26), Bingley: Emerald Publishing Group Limited, pp. 165-198.

Ivlevs, A. and T. Hinks (2015), 'Global Economic Crisis and Corruption', Public Choice, 162(3-4): 425-445.

Ivlevs, A. and T. Hinks (2018), 'Former Communist Party Membership and Bribery in the Post-Socialist Countries', Journal of Comparative Economics, 46(4): 1411-1424.

Jha, C. and B. Panda (2017), 'Individualism and Corruption: A Cross-Country Analysis', Economic Papers, 36(1): 60-74.

Kaasa, A., M. Vadi and U. Varblane (2014), 'Regional Cultural Differences within European Countries: Evidence from Multi-Country Surveys', Management International Review, 54(6): 825-852.

Kaufmann, D. and S.-J. Wei (2000) 'Does “Grease Money” Speed Up the Wheels of Commerce?' IMF Working Paper No. 00/64.

Kimenyi, M. (2011), 'Institutions and Development: The Primacy of Microanalysis', Journal of Institutional Economics, 7(4): 549-553.

Kirkman, B. L., K. B. Lowe and C. B. Gibson (2006), 'A Quarter Century of “Culture's Consequences": A Review of Empirical Research Incorporating Hofstede's Cultural Values Framework', Journal of International Business Studies, 37 (3): 285-320.

Kyriacou, A. (2016), 'Individualism-Collectivism, Governance and Economic Development', European Journal of Political Economy, 42(1): 91-104.

Ledeneva, A. (1998), Russia's Economy of Favours: Blat, Networking, and Informal Exchange, Cambridge and New York: Cambridge University Press.

Levin, M. and G. Satarov (2000), 'Corruption and Institutions in Russia', European Journal of Political Economy, 16(1): 113-132.

Libman, A. and A. Obydenkova (2013), 'Communism or Communists? Soviet Legacies and Corruption in Transition Economies', Economics Letters, 119(1): 101-103.

Licht, A., C. Goldschmidt and S. Schwartz (2007), 'Culture Rules: The Foundations of the Rule of law and Other Norms of Governance', Journal of Comparative Economics, 35(4): 659-688.

Lough, J. and V. Dubrovskiy (2018), 'Are Ukraine's Anti-Corruption Reforms Working?', Chatham House Research Paper. Accessed online: https://www.chathamhouse.org/2018/11/are-ukraines-anti-corruption-reforms-working.

Mazar, N. and D. Ariely (2006), 'Dishonesty in Everyday Life and Its Policy Implications', Journal of Public Policy and Marketing, 25(1): 117-126.

Mokyr, J. (1990), The Lever of Riches: Technological Creativity and Economic Progress, Oxford: Oxford University Press.

North, D. (1990), Institutions, Institutional Change and Economic Performance, Cambridge: University Press.

Oyserman, D., H. M. Coon and M. Kemmelmeier (2002), 'Rethinking Individualism and Collectivism: Evaluation of Theoretical Assumptions and Meta-Analyses', Psychological Bulletin, 128(1): 1773-1775.

Pitlik, H. and M. Rode (2017), 'Individualistic Values, Institutional Trust, and Interventionist Attitudes', Journal of Institutional Economics, 13(3): 575-598.

Rothstein, B. (2018), 'Fighting Systemic Corruption: The Indirect Strategy', Daedalus, 147(3): 35-49.

Schwartz, S. H. (1990), 'Individualism-Collectivism: Critique and Proposed Refinements', Journal of Cross-Cultural Psychology, 21(2): 139-157.

Schwartz, S. H. (1994), 'Beyond Individualism/Collectivism: New Cultural Dimensions of Values', in U. Kim, H. C. Triandis, Ç. Kâğitçibaşi, S.-C. Choi, and G. Yoon (eds), Cross-Cultural Research and Methodology Series. Individualism and Collectivism: Theory, Method, and Applications (Vol. 18 vols, Thousand Oaks, CA: Sage Publications, Inc, pp. 85-119.

Schwartz, S. H. and A. Bardi (2001), 'Value Hierarchies Across Cultures: Taking a Similarities Perspective', Journal of Cross-Cultural Psychology, 32(3): 268-290.

Singelis, T., H. Triandis, D. Bhawuk and M. Gelfand (1995), 'Horizontal and Vertical Dimensions of Individualism and Collectivism: A Theoretical and Measurement Refinement', Cross-Cultural Research, 29(3): 240-275.

Tanzi, V. (1994), 'Corruption, Governmental Activities and Markets', IMF Working Paper 94/99, Washington D.C.

Triandis, H. C. (2001), 'Individualism-Collectivism and Personality', Journal of Personality, 69(6): 907-924.

$\mathrm{Tu}, \mathrm{W}$., J. Yang and Y. Zheng (2020), 'Influence of Individual Values on Attitudes toward Corruption: What Undermine Formal Anticorruption Effectiveness', Asian Journal of Social Psychology, 23(3): 264-277.

Weaver, R. K. (2015), 'Getting People to Behave: Research Lessons for Policy Makers', Public Administration Review, 75(6): 806-816.

Zheng, X., S. E. Ghoul, O. Guedhami and C. Kwok (2013), 'Collectivism and Corruption in Bank Lending', Journal of International Business Studies, 44(4): 363-390. 


\section{Appendix}

\section{Sample description}

Table A1. Descriptive statistics

\begin{tabular}{|c|c|c|c|c|c|}
\hline & Obs & Mean & Std. Dev. & Min & Max \\
\hline \multicolumn{6}{|l|}{ Dependent variables } \\
\hline Ordinary difference (dummy) & 35,067 & 0.55 & 0.50 & 0.00 & 1.00 \\
\hline Court report (dummy) & 33,951 & 0.56 & 0.50 & 0.00 & 1.00 \\
\hline Acceptable report (dummy) & 34,801 & 0.49 & 0.50 & 0.00 & 1.00 \\
\hline Can do something (dummy) & 39,461 & 0.55 & 0.50 & 0.00 & 1.00 \\
\hline I report (dummy) & 34,107 & 0.64 & 0.48 & 0.00 & 1.00 \\
\hline \multicolumn{6}{|l|}{ Key independent variables } \\
\hline Individualism & 36,217 & 3.01 & 2.32 & -0.28 & 7.29 \\
\hline Relative inst. trust & 29,730 & 0.93 & 0.17 & 0.32 & 1.76 \\
\hline \multicolumn{6}{|l|}{ Main controls } \\
\hline Household income (In) & 32,182 & 8.94 & 2.87 & 0.00 & 21.49 \\
\hline Age & 40,670 & 48.58 & 17.47 & 18.00 & 95.00 \\
\hline Gender ( $1=$ male, $0=$ female $)$ & 40,670 & 0.43 & 0.49 & 0.00 & 1.00 \\
\hline Poor health & 40,670 & 0.14 & 0.35 & 0.00 & 1.00 \\
\hline Urban & 40,670 & 1.44 & 0.50 & 1.00 & 2.00 \\
\hline \multicolumn{6}{|l|}{ Marital status (ref. separated/widowed) } \\
\hline Single & 40,670 & 0.18 & 0.38 & 0.00 & 1.00 \\
\hline Married & 40,670 & 0.58 & 0.49 & 0.00 & 1.00 \\
\hline \multicolumn{6}{|l|}{ Additional controls } \\
\hline Breadth of corruption & 39,163 & 8.36 & 7.77 & 0.00 & 27.00 \\
\hline Corruption top problem in the country & 40,669 & 0.36 & 0.48 & 0.00 & 1.00 \\
\hline Take risks & 39,555 & 4.66 & 2.77 & 1.00 & 10.00 \\
\hline \multicolumn{6}{|l|}{ Religion (ref: agnostic/atheist) } \\
\hline Buddhist & 40,121 & 0.03 & 0.16 & 0.00 & 1.00 \\
\hline Jewish & 40,121 & 0.00 & 0.04 & 0.00 & 1.00 \\
\hline Orth. Christian & 40,121 & 0.39 & 0.49 & 0.00 & 1.00 \\
\hline Catholics & 40,121 & 0.21 & 0.41 & 0.00 & 1.00 \\
\hline Other Christian & 40,121 & 0.04 & 0.19 & 0.00 & 1.00 \\
\hline Muslims & 40,121 & 0.24 & 0.43 & 0.00 & 1.00 \\
\hline Others & 40,121 & 0.02 & 0.13 & 0.00 & 1.00 \\
\hline
\end{tabular}

Cite this article: Amini C, Douarin E, Hinks T (2022). Individualism and attitudes towards reporting corruption: evidence from post-communist economies. Journal of Institutional Economics 18, 85-100. https://doi.org/10.1017/S1744137420000648 